\title{
Rare earth element sorption onto hydrous manganese oxide A modeling study
}

\author{
Olivier Pourret $^{1^{*}}$ and Mélanie Davranche ${ }^{2}$
}

${ }^{1}$ HydrISE, Institut Polytechnique LaSalle Beauvais, 60026 Beauvais cedex, France

${ }^{2}$ Géosciences Rennes, Université Rennes 1, CNRS, 35042 Rennes cedex, France

Keywords: rare earth element, manganese oxyhydroxides, surface complexation modeling.

*Tel.: $\quad+33344068979 ; \quad$ Fax: $\quad+33344062526 ; \quad$ E-mail address:

olivier.pourret@lasalle-beauvais.fr. 


\begin{abstract}
Manganese oxides are important scavengers of rare earth elements (REE) in hydrosystems. However, it has been difficult to include Mn oxides in speciation models due to the lack of a comprehensive set of sorption reactions consistent with a given surface complexation model (SCM), as well as discrepancies between published sorption data and predictions using the available models. Surface complexation reactions for hydrous Mn oxide were described using a two surface site model and the diffuse double layer SCM. The specific surface area, surface side density and $\mathrm{pH}_{\mathrm{zpc}}$ were fixed to $746 \mathrm{~m}^{2} / \mathrm{g}, 2.1 \mathrm{mmol} / \mathrm{g}$ and 2.2 , respectively. Two site types ( $\equiv \mathrm{XOH}$ and $\equiv \mathrm{YOH})$ were also used with $\mathrm{pK}_{\mathrm{a} 2}$ values of $2.35(\equiv \mathrm{XOH})$ and $6.06(\equiv \mathrm{YOH})$. The fraction of the high affinity sites was fixed at 0.36 . Published REE sorption data were subsequently used to determine the equilibrium surface complexation constants, while considering the influence of $\mathrm{pH}$, ionic strength and metal loading. Log $\mathrm{K}$ increases from light REE to heavy REE and, more specifically, displays a convex tetrad effect. At low metal loading, the $\equiv \mathrm{YOH}$ site type strongly expresses its affinity towards REE whereas at higher metal loading, the same is true for the $\equiv \mathrm{XOH}$ site type. This study thus provides evidence for heterogeneity in the distribution of the Mn oxide binding sites among REE.
\end{abstract}

Keywords: lanthanide, manganese oxides, surface complexation modeling, PHREEQC, PhreePlot

\title{
1. Introduction
}

The distributions of rare earth elements (REE) in natural waters have been intensively investigated for more than forty years $[1,2]$. The absolute and relative concentrations of 14 stable REE have been determined in a variety of open ocean 
environments [3], estuaries [4], rivers [5], lakes [6], groundwaters [7], and hydrothermal fluids [8]. Although the complexation of hydrated trivalent REE with various inorganic anions (carbonate, hydroxide, sulfate, fluoride and chloride) has been intensively studied [9], REE partitioning and fractionation between solution and relevant mineral surfaces is much less understood. To date, few studies have been dedicated to REE sorption onto mineral surfaces [10-15] and the most frequently used solids were Fe-oxyhydroxides [10, 11, 13-15]. REE sorption by amorphous ferric hydroxide was measured over a $\mathrm{pH}$ range of 3.5 to 9.0 and over a large ionic strength (IS) range. For a constant $\mathrm{pH}$ and individual REE, the magnitude of the estimated distribution coefficients differs by a factor of around 400. Although Mnoxyhydroxides are as ubiquitous as Fe-oxyhydroxides and present high surface areas and a strong affinity for many elements [16], fewer studies have focused on REE adsorption by Mn-oxyhydroxides [10, 13, 17-19]. However, several studies have demonstrated that Mn-oxyhydroxides partly controlled REE fractionation and mobility in natural water. Thereby, they provided evidence that a negative $\mathrm{Ce}$ anomaly in solution is developed through the oxidation/scavenging of $\mathrm{Ce}$ (III) onto the $\mathrm{MnO}_{2}$ surface $[10,17,19]$. REE scavenging by ferromanganese nodules was also identified as a major process in controlling REE fractionation in seawater [8, 20, 21]. The lack of data for REE binding by Mn-oxyhydroxides may be attributed to the high variety of Mn-oxyhydroxide minerals and the heterogeneity of the published surface properties which complicate modeling studies. However, in order to accurately describe REE behavior, it is essential that REE binding to Mn-oxyhydroxides is quantitatively modeled. Many surface complexation models have been established to study and quantify cation sorption onto mineral surfaces. Each of them has their own solid-solution interface description, model parameters and set of thermodynamic data 
and many provide satisfactory fits to experimental data (e.g., [22]). Partially as a result of this model flexibility, ion sorption data on Mn-oxyhydroxides have been fit using a number of different surface complexation models (e.g. SCM). Thereby, a triple-layer SCM was used to evaluate and predict the surface complexation constants for hydrous manganese oxide (HMO) [23]. A variation on the constant capacitance model [24] was included in SCAMP to determine the model parameters for sorption on Mn oxyhydroxides [25]. Crystallographic data were used as the basis for a new surface complexation model formulation [26]. More recently, Tonkin et al. [16] provided consistent surface complexation constants for several cations for a generic HMO and a diffuse double layer SCM for a system in which HMO is an important scavenger.

In this study, a quantitative SCM model for REE sorption by HMO at low substrate loadings (from 1.6 to $100 \mathrm{mg} / \mathrm{L}$ ) was proposed using the generic HMO surface parameters provided by Tonkin et al. [16]. The REE-HMO binding constant was extrapolated using the linear free energy relationship (LFER) methodology and by fitting experimental datasets with the PhreePlot program [27]. Published experimental data cover an ionic strength range from 0 to $0.7 \mathrm{~mol} / \mathrm{L}$ and a relatively wide $\mathrm{pH}$ range from 4 to 9 [10]. This model was further used to discuss the nature and importance of REE sorption by manganese oxyhydroxides in the open ocean.

\section{Materials and methods}

\subsection{Surface complexation model description}

The diffuse double layer SCM describes the sorption of solutes onto oxide 
surfaces. This model is the central component of the generalized two-layer model used to compile the database of surface reactions for hydrous Fe(III) oxide (HFO) provided by Dzombak and Morel [28]. In this work, the SCM was chosen because of its relative simplicity and its success in describing cation sorption to HMO [16]. Surface equilibrium reactions are written as combination sorption reactions (Eq. 1 to 6) to specific hydroxyl sites on the oxide surface, to which a coulombic term that represents the electrochemical work of sorption is added. This coulombic term is calculated from the Gouy-Chapman electrical double layer theory and is included in the apparent equilibrium constants used by the model, $\mathrm{P}=\exp (-\mathrm{F} \psi / \mathrm{RT})$, where $\mathrm{F}$ is the Faraday constant, $\psi$ is the electrostatic potential, $\mathrm{r}$ is the gas constant and $\mathrm{T}$ is the absolute temperature.

$$
\begin{array}{lll}
\equiv \mathrm{X}-\mathrm{OH} \Leftrightarrow \equiv \mathrm{X}-\mathrm{O}^{-}+\mathrm{H}^{+} & \mathrm{K}_{\mathrm{a} 2 \equiv \mathrm{X}-\mathrm{OH}} \\
\equiv \mathrm{Y}-\mathrm{OH} \Leftrightarrow \equiv \mathrm{Y}-\mathrm{O}^{-}+\mathrm{H}^{+} & \mathrm{K}_{\mathrm{a} 2 \equiv \mathrm{Y}-\mathrm{OH}} \\
\equiv \mathrm{X}-\mathrm{OH}+\mathrm{M}^{\mathrm{n}+} \Leftrightarrow \equiv \mathrm{X}-\mathrm{OM}^{(\mathrm{n}-1)+}+\mathrm{H}^{+} & \mathrm{K}_{\equiv \mathrm{X}-\mathrm{OM}} \\
\equiv \mathrm{X}-\mathrm{OH}+\mathrm{M}^{\mathrm{n}+}+\mathrm{H}_{2} \mathrm{O} \Leftrightarrow \equiv \mathrm{X}-\mathrm{OMOH}^{(\mathrm{n}-2)+}+2 \mathrm{H}^{+} & \mathrm{K}_{\equiv \mathrm{X}-\mathrm{OMOH}} \\
\equiv \mathrm{Y}-\mathrm{OH}+\mathrm{M}^{\mathrm{n}+} \Leftrightarrow \equiv \mathrm{Y}-\mathrm{OM}^{(\mathrm{n}-1)+}+\mathrm{H}^{+} & \mathrm{K}_{\equiv \mathrm{Y}-\mathrm{OM}} \\
\equiv \mathrm{Y}-\mathrm{OH}+\mathrm{M}^{\mathrm{n}+}+\mathrm{H}_{2} \mathrm{O} \Leftrightarrow \equiv \mathrm{Y}-\mathrm{OMOH}^{(\mathrm{n}-2)+}+2 \mathrm{H}^{+} & & \mathrm{K}_{\equiv \mathrm{Y}-\mathrm{OMOH}}
\end{array}
$$

The HMO surface properties (specific surface area (SSA), surface site density, and acidity constants), REE-HMO stability constants and concentration of a nonspecifically adsorbing electrolyte solution are required. Data for HMO were obtained from Tonkin et al. [16] (Table 1). The SSA value input to the model fixed at $746 \mathrm{~m}^{2} / \mathrm{g}$ is calculated and is therefore higher than the values determined by the BET- $\mathrm{N}_{2}$ method, which range from 0.048 to $359 \mathrm{~m}^{2} / \mathrm{g}$ [29]. The total HMO concentration of the surface sites $(\mathrm{mol} / \mathrm{g}$ ) was divided into fractions for the two site types $(\equiv \mathrm{XOH}$ and $\equiv \mathrm{YOH}$ ), which present high and low affinity for REE binding, respectively. REE sorption onto HMO is therefore simulated assuming that two types of sites are 
available on the oxide surface (Table 1). Modeling calculations were performed with PHREEQC and PhreePlot $[27,30]$. Three keyword data blocks are required to define the surface-complexation data for a simulation: (i) SURFACE_MASTER_SPECIES, (ii) SURFACE_SPECIES, and (iii) SURFACE. The SURFACE_MASTER_SPECIES data block defines a binding site, named "Hmo" (HMO; [16]), with two binding sites, "Hmo_w" and "Hmo_s", for the "weak" and "strong" binding sites. Inorganic speciation was then performed; the Nagra/PSI database [31] was used and updated including the same well-accepted stability constants at infinite dilution $\left(25^{\circ} \mathrm{C}\right)$ for the REE inorganic complexes (hydroxide, sulfate and carbonate; [32-34]. As Bau and Koschinsky [35] proposed, Ce(III) is oxidized after its sorption onto oxyhydroxide and therefore only REE(III) were considered in the proposed SCM.

\subsection{REE-HMO sorption stability constants}

\subsubsection{Extrapolation of the linear free energy relationship}

The linear free energy relationship (LFER) or the correlation between the first hydrolysis constant for aqueous species and the corresponding surface complexation constant was used to estimate the sorption stability constant as has been previously done in numerous studies $[16,28,36,37]$. The LFER can be used to extend results from a limited dataset to other metals. The REE-HMO stability constants were estimated by the same extrapolation method used by Tonkin et al. [16]. These authors observed that a LFER exists for HMO between $\log \mathrm{K}_{\equiv \mathrm{XOMe}}, \log \mathrm{K}_{\equiv \mathrm{XOMeOH}}, \log \mathrm{K}_{=\mathrm{YOMe}}$ and $\log \mathrm{K}_{\equiv \mathrm{YOMeOH}}$ and the first hydrolysis $(\mathrm{OH})$ constant for the metals (log $\mathrm{K}_{\mathrm{MeOH}}$ ). 
However, Tonkin et al. [16] caution against assuming a LFER for all metals on HMO, notably with regards to the possible oxidation/scavenging mechanisms on the HMO surface. The estimated stability constant of REE binding to HMO is reported in Table 2 . The first hydrolysis constant of REE, $\log \mathrm{K}_{\mathrm{REE}-\mathrm{OH}}$, is taken from the NIST database [38]. The REE-HMO stability constants extrapolated from the LFER methodology are listed in Table 3 with the REE-OH stability constant used for the calculation.

\subsubsection{PhreePlot modeling}

The $\mathrm{pKa}_{2}, \alpha$ values and published REE sorption data [10] were subsequently used to determine the equilibrium surface complexation constants for the whole REE series $\left([\mathrm{REE}]=125 \mu \mathrm{g} / \mathrm{L} ;\left[\mathrm{HMO}=\delta-\mathrm{MnO}_{2}\right]=10 \mathrm{mg} / \mathrm{L}\right.$; room temperature; IS fixed with $\mathrm{NaNO}_{3}$; no control of the $\mathrm{CO}_{2}$ species). They were modeled using the computer program PhreePlot [27] and the Nagra/PSI database [31], which was modified to include the well-accepted infinite dilution (at $25^{\circ} \mathrm{C}$ ) of inorganic species [32, 33]. Intrinsic constants for the surface complexation model were optimized by Powell's non-linear least squares method using PhreePlot's fitting options. The REE-HMO stability constants are listed in Table 4 . Only $\log \mathrm{K}_{\equiv \mathrm{XOMe}}$ and $\log \mathrm{K}_{\equiv \mathrm{YOMe}}$ were further considered because $\log \mathrm{K}_{\equiv \mathrm{XOMeOH}}$ and $\log \mathrm{K}_{\equiv \mathrm{YOMeOH}}$ are low and thus negligible.

\section{Results and discussion}

The speciation calculations presented below were performed using a diffuse double layer SCM in the PhreePlot program with the LFER extrapolated and PhreePlot fitted REE-HMO stability constants. The database was modified to 
integrate the extrapolated and fitted REE-HMO stability constant, as well as the infinite dilution $\left(25^{\circ} \mathrm{C}\right)$ stability constants for the REE inorganic (chloride and carbonate) complexes $[32,33]$. To test the validity of the extrapolated and fitted REEHMO stability constant and the diffused double layer SCM, the modeling calculations were compared to the REE-HMO sorption experimental datasets [10, 13, 18, 19].

\subsection{REE-HMO modeling with extrapolated stability constant}

\subsubsection{LFER extrapolated stability constant}

The dataset for the extrapolated REE-HMO stability constants was subsequently used to calculate the distribution of La under various experimental conditions $[10,13,18]$. The comparison between the experimental and calculated data provide evidence that the dataset for the extrapolated REE-HMO stability constants cannot be used to reproduce the experimental distribution of REE onto HMO regardless of the $\mathrm{pH}$, IS (Figure 1; $\mathrm{pH}$ ranging from 4.0 to 9.5 and IS varying from 0.001 to $0.7 \mathrm{~mol} / \mathrm{L}$ ) and metal loading ([REE] varying from $5 \mu \mathrm{g} / \mathrm{L}$ to $0.2 \mathrm{mg} / \mathrm{L}$ and $\left[\mathrm{HMO}=\delta-\mathrm{MnO}_{2}\right]$ ranging from $3.2 \mathrm{mg} / \mathrm{L}$ to $\left.100 \mathrm{mg} / \mathrm{L}\right)$. The calculated proportion of bound REE is strongly underestimated. Therefore, the datasets for the extrapolated constants were not used hereafter.

\subsubsection{PhreePlot fitted stability constants}

The fitted stability constants were subsequently used to calculate the distribution of $\mathrm{La}, \mathrm{Eu}$ and $\mathrm{Lu}$ under De Carlo et al.'s [10] experimental conditions. 
Figure 2 compares the experimental and calculated datasets. The model reproduces reasonably well the increasing light REE (LREE; illustrated by La) binding onto HMO with pH and IS. However, for heavy REE (HREE; illustrated by Lu), although the model predicts a decreasing binding strength, the experimental data show that $100 \%$ of REE are sorbed onto HMO. In Table 5, the rmse (root mean square errors) are reported between the experimental and modeling data for the three REE and IS conditions. The important rmse values for $\mathrm{Eu}$ and $\mathrm{Lu}$ at $\mathrm{IS}=0.7$ were expected with regards to the irregularity observed in the experimental dataset [10]. Moreover, Figure 2 shows that the discrepancy between the experimental and calculated data also increases with $\mathrm{pH}$, IS and the REE atomic number. Lee and Byrne [39] demonstrated that REE binding by carbonate in solution increases with the REE atomic numbers. The most important difference observed for the heavy REE (HREE) therefore indicates that the model predicts larger concentrations of HREE bound to carbonate than in the experimental conditions.

\subsection{PhreePlot modeling}

\subsection{1. $\mathrm{pH}$ dependence}

Figure 2 also compares the experimental and calculated datasets. The model reproduces reasonably well the increasing LREE binding onto HMO with $\mathrm{pH}$ and IS. However, the model predicts a decreasing binding strength at an alkaline $\mathrm{pH}$ for HREE. As already shown by De Carlo et al. [10], a large extent of the variability in the sorption efficiency is observed at low $\mathrm{pH}$ with the IS. This is generally evidenced by a shift in the adsorption edges towards an alkaline $\mathrm{pH}$ and reduced REE sorption with increasing IS, especially at an acidic $\mathrm{pH}$. The differences appear more pronounced for LREE than HREE. 


\subsubsection{REE patterns}

The REE distribution between suspended HMO (at an IS of $0.5 \mathrm{~mol} / \mathrm{L}$ ) over the $\mathrm{pH}$ range from 4.79 to 6.80 [13] was further modeled using the previously described SCM procedure. The calculated REE patterns onto HMO are shown in Figure 3a. The patterns exhibit extremely large positive Ce anomalies and a convex tetrad effect (well developed for the first two tetrads). These two features were already apparent in the experimental datasets of De Carlo et al. [10] and Ohta and Kawabe [13]. The same features occur for Davranche et al.'s [18] dataset: the REE patterns exhibit large positive Ce anomalies (Fig. 3b), as well as convex tetrad curves. However, they are less developed. This discrepancy might be explained by the rather different experimental conditions used in Davranche et al. [18] as compared to those used in De Carlo et al. [10] from which the constants are derived.

Among these results, an interesting feature is that the modeling approach reproduces the strongly enhanced adsorption of $\mathrm{Ce}$ from acidic solution by HMO, relative to the other REE. The adsorption edge in the HMO suspension is therefore below $\mathrm{pH} 4$ for Ce, whereas for strictly trivalent REE, it occurs near neutral $\mathrm{pH}$. It should be noted that at ambient conditions and in the absence of strong ligands, tetravalent $\mathrm{Ce}$ is only stable in solid phase [40], or when it is derived from the oxidation/scavenging of Ce(III) onto the metal oxyhydroxide surface [35]. Thus, the Ce-HMO constant calculated in this study is a conditional constant which considers the global oxidationscavenging of the $\mathrm{Ce}(\mathrm{III}, \mathrm{IV})$ mechanism onto the HMO surface.

\subsubsection{Model validity and application}


In order to check the validity of the model, calculations were performed with data from the literature $[13,18]$. Irrespective of the $\mathrm{pH}$, IS (Figure 1; $\mathrm{pH}$ ranging from 4.0 to 9.5 and IS varying from 0.001 to $0.7 \mathrm{~mol} / \mathrm{L}$ ) and metal loadings ([REE] varying from $5 \mu \mathrm{g} / \mathrm{L}$ to $0.2 \mathrm{mg} / \mathrm{L}$ and $\left[\mathrm{HMO}=\delta-\mathrm{MnO}_{2}\right]$ ranging from $3.2 \mathrm{mg} / \mathrm{L}$ to $100 \mathrm{mg} / \mathrm{L}$ ), the modeling is in agreement with the experimental results. In further detail, data from Ohta and Kawabe [13] for a high IS (i.e., $0.5 \mathrm{~mol} / \mathrm{L}$ ) are well reproduced, as was observed in De Carlo et al.'s [10] experimental conditions. However, data from Davranche et al. [18] for the lowest IS (i.e., $0.001 \mathrm{~mol} / \mathrm{L}$ ) are not well reproduced. The main differences between these experimental conditions, apart from the IS, are that different metal loadings are tested (i.e., 0.875 for Ohta and Kawabe [13]; 0.175 for De Carlo et al. [10]; 0.0007 for Davranche et al. [18, 19]).

Unlike the various experimental conditions, differences between the experimental observations and modeling are probably due to the generic parameters chosen to represent the Mn-oxyhydroxides. In fact, there are different Mn-oxyhydroxide varieties and their properties are highly variable [29, 41]. As an example, $\mathrm{pH}_{\mathrm{zpc}}$ values for HMO can vary from 2 to 9.6 [29]. Ohta and Kawabe [13] and De Carlo et al. [10] consider vernadite with a $\mathrm{pH}_{\mathrm{zpc}}$ of 2.25 [42], whereas Davranche et al. [18] consider pyrolusite with a $\mathrm{pH}_{\mathrm{zpc}}$ of 5.8 .

Apart from these discrepancies, a faithful reproduction of the data from the literature constitutes an even better test of model's ability. While the conditional nature (IS, pH and metal loading) of the determined stability constants would render such an exercise rather meaningless for a single element, the unique attributes of the REE series can be used to examine whole log K patterns. The REE pattern shape (i.e., REE fractionation) is governed by the chemical properties of the REE and does not depend 
on the sorbent properties, which depend on its synthesis method which controls, for example, its crystallinity and specific surface area. [43]

This type of SCM development can be used to improve the understanding of REE fractionation in seawater. Indeed, the experimental conditions are closed to those of marine system. Moreover, an interesting feature is that modeling approach can reproduce the high adsorption of Ce relative to the other REE under acidic conditions. This behavior is also observed in seawater when dissolved REE are scavenged by $\delta$ $\mathrm{MnO}_{2}$ [10]. The Ce anomaly is recognized as one of the fundamental features of lanthanide geochemistry due to its redox sensitivity [44]. Cerium is a prime proxy for ocean-atmosphere evolution over geological timescales [45]. The contribution of oxidative scavenging toward the removal of Ce from solution is most pronounced at acidic $\mathrm{pH}$, where the strictly trivalent REE exhibit little propensity for sorption onto $\delta-\mathrm{MnO}_{2}$. It has been suggested that the behavior of $\mathrm{REE}$ and $\mathrm{Ce}$ in the marine environment is more closely coupled to that of $\mathrm{Mn}$ than to that of $\mathrm{Fe}$ due to the oxidative scavenging of Ce by Mn-oxyhydroxides [44].

\section{Concluding remarks}

Surface complexation modeling was used to test REE sorption onto HMO by considering LFER to determine log K. However, this methodology does not allow experimental data to be reproduced. Therefore, these experimental data were further used to extrapolate equilibrium surface complexation constants by fitting them for a large dataset [10]. The determined constants can reproduce $\mathrm{pH}$ dependence and REE fractionation over a wide variety of conditions (i.e., $\mathrm{pH}$ ranging from 4.0 to 9.5 , IS varying from 0.001 to $0.7 \mathrm{~mol} / \mathrm{L}$, [REE] varying from $5 \mu \mathrm{g} / \mathrm{L}$ to $0.2 \mathrm{mg} / \mathrm{L}$ and 
$\left[\mathrm{HMO}=\delta-\mathrm{MnO}_{2}\right]$ ranging from $3.2 \mathrm{mg} / \mathrm{L}$ to $100 \mathrm{mg} / \mathrm{L}$ ). SCM development of this type can be used to improve the understanding of REE fractionation in seawater. However, these results emphasize the relevance of conducting further experiments and modeling for a better understanding of natural systems and have considerable implications for the assessment of REE mobility.

\section{Acknowledgments}

Dr. Atsuyuki Ohta is acknowledged for sharing the raw data used in this study. This research was funded by the French ANR, through the "Programme Jeunes Chercheuses - Jeunes Chercheurs: SURFREE (Rare earth elements partitioning at solid-water interface: Impact on REE geochemical behaviour and tracing properties)".

Dr. Sara Mullin is acknowledged for post-editing the English content. 


\section{Tables and Figures Captions}

Table 1 SCM parameters for HMO [16].

Table 2 Stability constants used for the LFER established by Tonkin et al. [16].

Table 3 REE-HMO stability constants extrapolated from the LFER established by Tonkin et al. [16].

Table 4 REE-HMO stability constants fitted with PhreePlot from De Carlo et al.'s [10] experimental datasets.

Table 5 Rmse (root mean square error) calculated between the experimental datasets [10]and the datasets calculated from the REE-HMO fitted stability constant.

Figure 1 Proportion of La sorbed to HMO as a function of $\mathrm{pH}$. The dots correspond to experimental data from the literature and the solid line representes modeled data using extrapolated constants obtained from LFER (a) (b) (c) De Carlo et al. [10]; (d) Ohta and Kawabe [13]; (e) Davranche et al. [18].

Figure 2 A comparison between the experimental and calculated proportion of La, Eu and $\mathrm{Lu}$ bound to $\mathrm{HMO}$ using the fitted REE-HMO stability constants under the experimental condition's provided by De Carlo et al. [10]. The dots correspond to the displayed experimental data and the solid line corresponds to the calculated data.

Figure 3 Modeled vs. experiments REE patterns showing $\mathrm{Ce} / \mathrm{Ce} *$ for the experimental conditions described in (a) Fig. 2 in Ohta and Kawabe [13], and (b) Fig. 4 in Davranche et al. [19] and Fig. 6 in Davranche et al. [18]. 
1

2

3

4

5

6

7

8

9
10

11

12

13

14

15

16

17

18

19

20

21

22

23

24

25

26
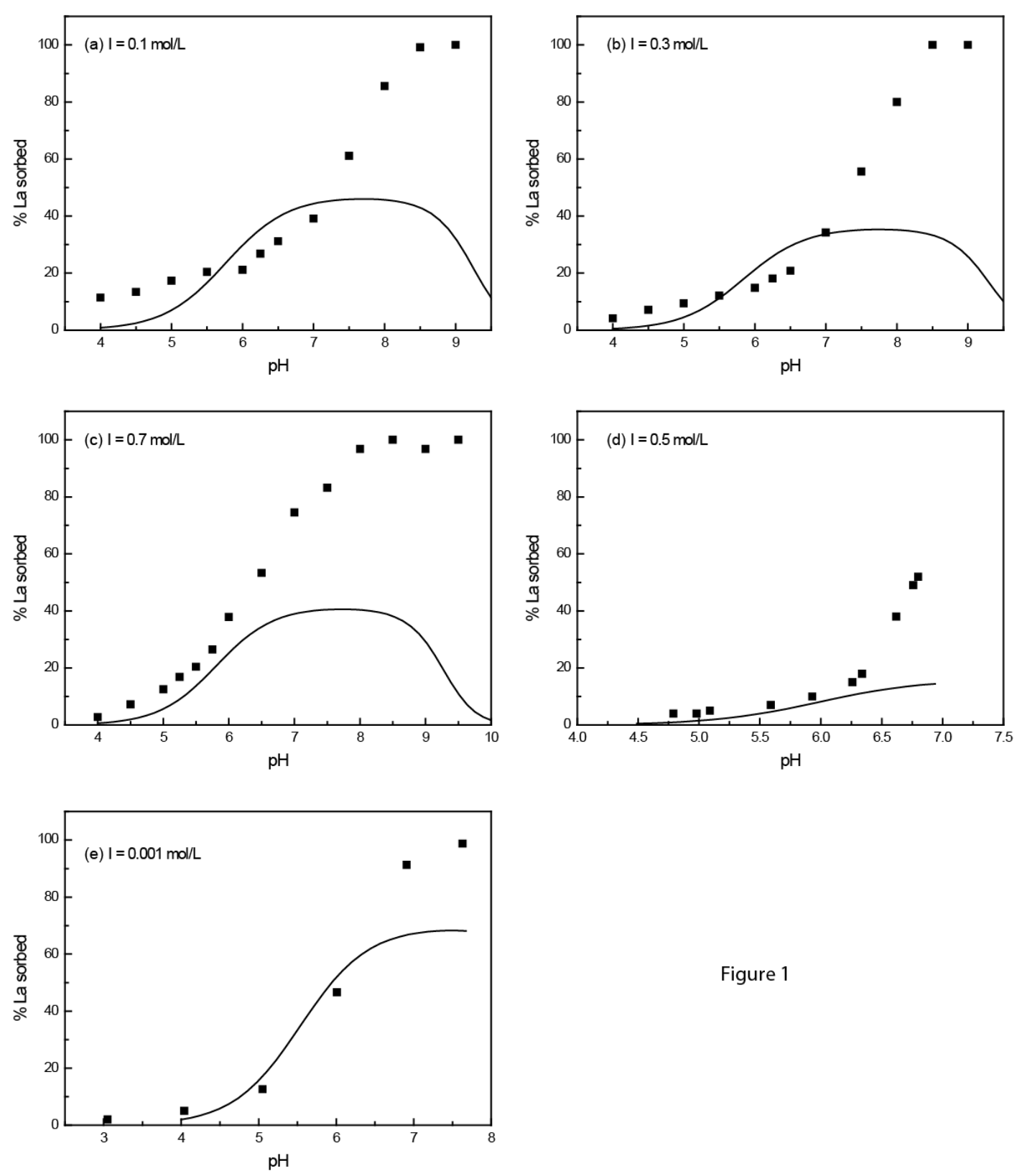

Figure 1 

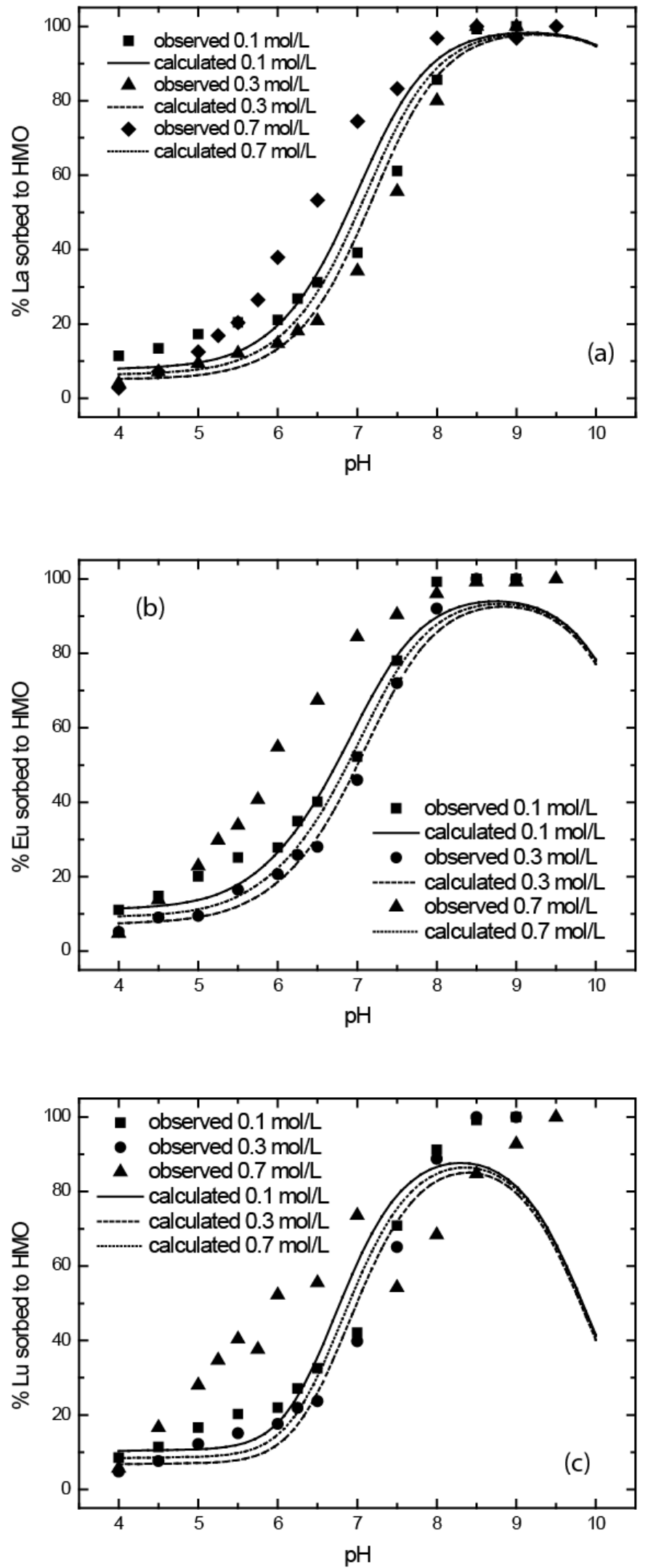

Figure 2 

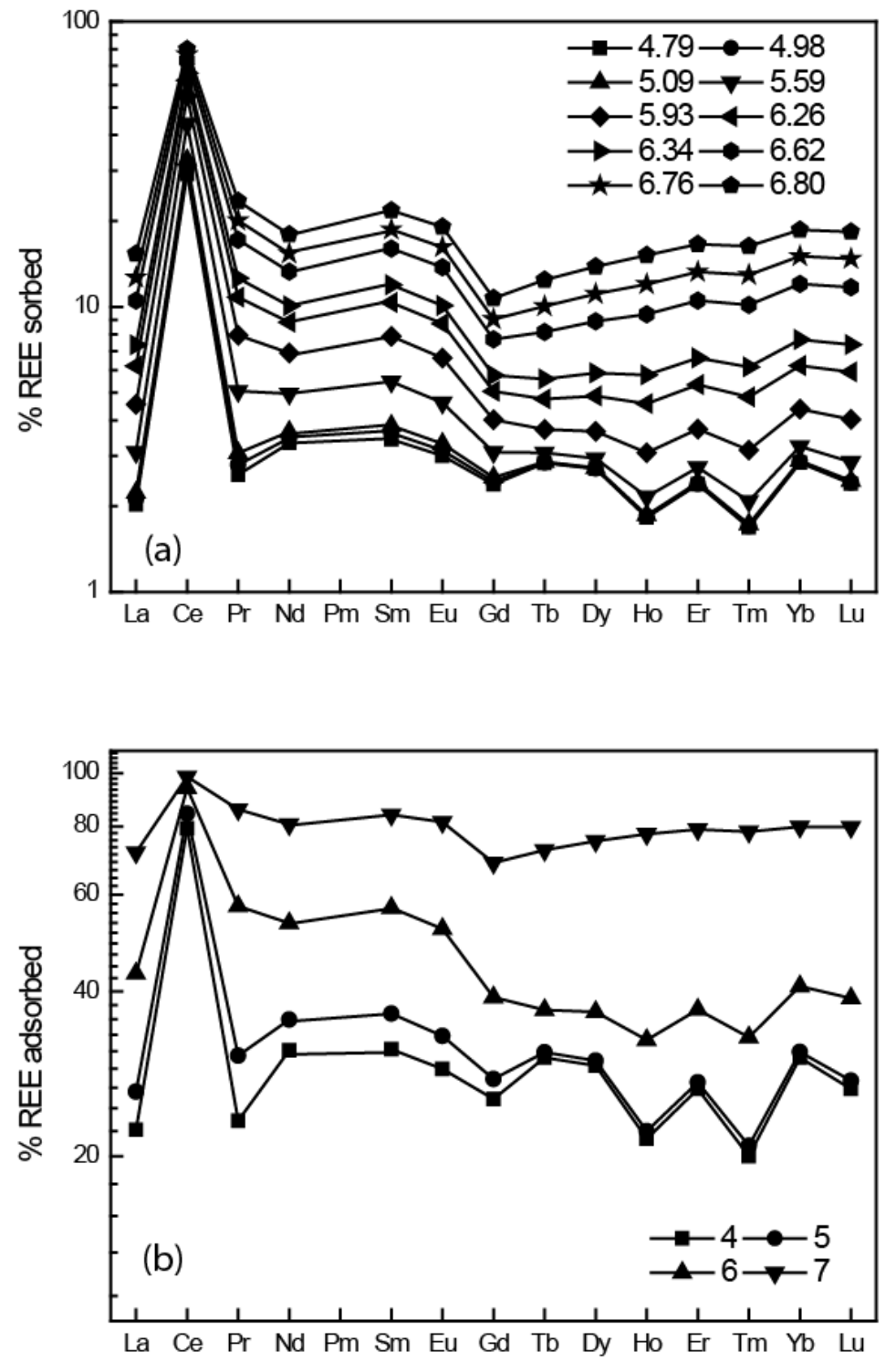

Figure 3 
Table 1.

\begin{tabular}{cccccc}
\hline $\mathrm{pK}_{\mathrm{a} 1}$ & $\mathrm{pK}_{\mathrm{a} 2}$ & $\begin{array}{c}\mathrm{SSA} \\
\left(\mathrm{m}^{2} / \mathrm{g}^{-1}\right)\end{array}$ & $\begin{array}{c}\text { Total site density } \\
(\mathrm{mmol} / \mathrm{g})\end{array}$ & $\begin{array}{c}\text { Strong' site } \\
\text { density } \\
(\equiv \mathrm{XOH})\end{array}$ & $\begin{array}{c}\text { 'Weak' site } \\
\text { density } \\
(\equiv \mathrm{mOH})\end{array}$ \\
\hline 2.35 & 6.06 & 746 & 2.1 & 1.34 & 0.76 \\
\hline
\end{tabular}


1

Table 2.

\begin{tabular}{cccccc}
\hline & $\log \mathbf{K}_{\mathrm{MeOH}}$ & $\log \mathbf{K}_{\equiv \mathbf{X O M e}}$ & $\log \mathbf{K}_{\equiv \mathbf{X O M e O H}}$ & $\log \mathbf{K}_{\equiv \text { YOMe }}$ & $\log \mathbf{K}_{\equiv \text { УOMeOH }}$ \\
\hline $\mathbf{B a}$ & 0.53 & 0.45 & - & - & - \\
$\mathbf{C a}$ & 1.15 & -1.5 & - & - & - \\
$\mathbf{C d}$ & 3.92 & -2.4 & -8 & -3.5 & -8.5 \\
$\mathbf{C o}$ & 4.35 & 1 & -3.9 & - & - \\
$\mathbf{C u}$ & 6.5 & 0.85 & -2.8 & 0.86 & -5.7 \\
$\mathbf{M g}$ & 2.56 & -2.4 & -7.7 & - & - \\
$\mathbf{M n}$ & 3.41 & 1.2 & -2.7 & - & - \\
$\mathbf{N i}$ & 4.14 & -0.48 & -5 & - & - \\
$\mathbf{P b}$ & 6.29 & - & -0.86 & 3.4 & -1.6 \\
$\mathbf{S r}$ & 0.71 & -1.6 & -6.6 & - & - \\
$\mathbf{Z n}$ & 5.04 & -0.01 & -4.4 & - & -7.6 \\
\hline
\end{tabular}


Table 3.

\begin{tabular}{cccccc}
\hline & $\log \mathbf{K}_{\mathrm{MeOH}}$ & $\log \mathbf{K}_{\equiv \mathbf{X O M e}}$ & $\log \mathbf{K}_{=\mathbf{X O M e O H}}$ & $\log \mathbf{K}_{\equiv \text { YOMe }}$ & $\log \mathbf{K}_{\equiv \text { ХOMeOH }}$ \\
\hline La & 5.19 & 0.05 & -3.67 & -0.58 & -6.34 \\
Ce & 5.66 & 0.17 & -3.23 & 0.45 & -5.41 \\
Pr & 5.68 & 0.18 & -3.22 & 0.50 & -5.37 \\
Nd & 5.82 & 0.22 & -3.09 & 0.80 & -5.10 \\
Sm & 6.16 & 0.31 & -2.78 & 1.55 & -4.43 \\
Eu & 6.24 & 0.33 & -2.70 & 1.73 & -4.27 \\
Gd & 6.17 & 0.31 & -2.77 & 1.57 & -4.41 \\
Tb & 6.36 & 0.37 & -2.59 & 1.99 & -4.03 \\
Dy & 6.41 & 0.38 & -2.55 & 2.10 & -3.94 \\
Ho & 6.44 & 0.39 & -2.52 & 2.17 & -3.88 \\
Er & 6.48 & 0.40 & -2.48 & 2.25 & -3.80 \\
Tm & 6.61 & 0.43 & -2.36 & 2.54 & -3.54 \\
Yb & 6.76 & 0.48 & -2.23 & 2.87 & -3.25 \\
Lu & 6.73 & 0.47 & -2.25 & 2.80 & -3.30 \\
\hline
\end{tabular}


1

2

4

5

9

10

11

12

13

14

15

16

17

18

19

20

21

22

23

24

25

26

27

28

29

30

31

32

33

34

35

36

37

38

39

40

41

42

43

44

45

46

47

48

49

50

51

52

53

54

55

56

57

58

59

60

61

62

63

64

65

Table 4

\begin{tabular}{ccc}
\hline & $\log \mathbf{K}_{\equiv \text { XOMe }}$ & $\log \mathbf{K}_{=\text {YOMe }}$ \\
\hline La & -0.47 & 2.50 \\
Ce & 1.02 & 3.73 \\
Pr & -0.15 & 2.51 \\
Nd & -0.33 & 2.70 \\
Sm & -0.24 & 2.70 \\
Eu & -0.37 & 2.65 \\
Gd & -0.73 & 2.58 \\
Tb & -2.35 & 2.69 \\
Dy & -2.51 & 2.67 \\
Ho & -2.37 & 2.49 \\
Er & -1.79 & 2.61 \\
Tm & -1.55 & 2.45 \\
Yb & -3.86 & 2.69 \\
Lu & -1.49 & 2.61 \\
\hline
\end{tabular}


1

2

4

5

7

8

9

10

11

12

13

14

15

16

17

18

19

20

21

22

23

24

25

26

27

28

29

30

31

32

33

34

35

36

37

38

39

40

41

42

43

44

45

46

47

48

49

50

51

52

53

54

55

56

57

58

59

60

61

62

63

64

65

Table 5

\begin{tabular}{cccc}
\hline & La & Eu & Lu \\
\hline IS $=\mathbf{0 . 1}$ & 0.05 & 0.04 & 0.06 \\
$\mathbf{I S}=\mathbf{0 . 3}$ & 0.04 & 0.03 & 0.35 \\
$\mathbf{I S}=\mathbf{0 . 7}$ & 0.07 & 0.23 & 0.34 \\
\hline
\end{tabular}




\section{References}

[1] E. D. Goldberg, M. Koide, R. A. Schmitt, R. H. Smith, J. Geophys. Res. 68 (1963) 4209-4217.

[2] P. Henderson, Rare earth element geochemistry, Elsevier, Amsterdam, 1984.

[3] H. J. W. De Baar, M. P. Bacon, P. G. Brewer, K. W. Bruland, Geochim. Cosmochim. Acta 49 (1985) 1943-1959.

[4] E. R. Sholkovitz, H. Elderfield, Global Biogeochem. Cy. 2 (1988) 157-176.

[5] S. J. Goldstein, S. B. Jacobsen, Earth Planet. Sci. Lett. 89 (1988) 35-47.

[6] K. H. Johannesson, W. B. Lyons, D. A. Bird, Geophys. Res. Lett. 21 (1994) 773-776.

[7] P. L. Smedley, Geochim. Cosmochim. Acta 55 (1991) 2767-2779.

[8] M. Bau, Contrib. Mineral. Petrol. 123 (1996) 323-333.

[9] S. A. Wood, Chem. Geol. 82 (1990) 159-186.

[10] E. H. De Carlo, X.-Y. Wen, M. Irving, Aquat. Geochem. 3 (1998) 357-389.

[11] M. Bau, Geochim. Cosmochim. Acta 63 (1999) 67-77.

[12] A. Ohta, I. Kawabe, Geochem. J. 34 (2000) 439-454.

[13] A. Ohta, I. Kawabe, Geochim. Cosmochim. Acta 65 (2001) 695-703.

[14] K. A. Quinn, R. H. Byrne, J. Schijf, Aquat. Geochem. 10 (2004) 59-80.

[15] J. Schijf, K. S. Marshall, Mar. Chem. 123 (2011) 32-43.

[16] J. W. Tonkin, L. S. Balistrieri, J. W. Murray, Appl. Geochem. 19 (2004) 29-

53.

[17] D. Koeppenkastrop, E. H. De Carlo, Chem. Geol. 95 (1992) 251-263.

[18] M. Davranche, O. Pourret, G. Gruau, A. Dia, D. Jin, D. Gaertner, Chem. Geol. 247 (2008) 154-170.

[19] M. Davranche, O. Pourret, G. Gruau, A. Dia, M. Le Coz-Bouhnik, Geochim. Cosmochim. Acta 69 (2005) 4825-4835.

[20] D. Z. Piper, Geochim. Cosmochim. Acta 38 (1974) 1007-1022.

[21] H. Elderfield, C. J. Hawkesworth, M. J. Greaves, S. E. Calvert, Geochim. Cosmochim. Acta 45 (1981) 513-528.

[22] P. Venema, T. Hiemstra, W. H. van Riemsduk, J. Colloid Interface Sci. 181 (1996) 45-59.

[23] R. W. Smith, E. A. Jenne, Environ. Sci. Technol. 25 (1991) 525-531.

[24] P. W. Schindler, W. Stumm, in: The surface chemistry of oxides, hydroxides and oxide minerals, W. Stumm (Ed.), Wiley: 1987, pp 83-110.

[25] S. Lofts, E. Tipping, Geochim. Cosmochim. Acta 62 (1998) 2609-2625.

[26] C. A. J. Appelo, D. Postma, Geochim. Cosmochim. Acta 63 (1999) 30393048.

[27] D. G. Kinniburgh, D. M. Cooper PhreePlot: Creating graphical output with PHREEQC, Available at: http://www.phreeplot.org: 2009.

[28] D. A. Dzombak, F. M. M. Morel, Surface complexation modeling-Hydrous ferric oxide, Wiley New York, 1990.

[29] M. Kosmulski, Surface Charging and Points of Zero Charge, CRC Press, Boca Raton, 2009.

[30] D. L. Parkhurst, C. A. J. Appelo, User's guide to PHREEQC (Version 2) - A computer program for speciation, batch-reaction, one-dimensional transport, and inverse geochemical calculations, 99-4259, U.S. Geological Survey Water-Resources Investigations Report, 1999, p 309. 
[31] W. Hummel, U. Berner, E. Curti, F. J. Pearson, T. Thoenen, Nagra / PSI Chemical Thermodynamic Data Base 01/01, Universal Publishers, Parkland, Florida, 2002.

[32] G. D. Klungness, R. H. Byrne, Polyhedron 19 (2000) 99-107.

[33] Y.-R. Luo, R. H. Byrne, Geochim. Cosmochim. Acta 68 (2004) 691-699.

[34] J. Schijf, R. H. Byrne, Geochim. Cosmochim. Acta 68 (2004) 2825-2837.

[35] M. Bau, A. Koschinsky, Geochem. J. 43 (2009) 37-47.

[36] J. Tang, K. H. Johannesson, Geochim. Cosmochim. Acta 67 (2003) 23212339.

[37] O. Pourret, M. Davranche, G. Gruau, A. Dia, Chem. Geol. 243 (2007) 128141.

[38] A. E. Martell, R. M. Smith, R. J. Motekaitis, NIST Critically Selected Stability Constants of Metal Complexes Database. Version 8.0 for Windows, National Institute of Standards and Technology, Texas A\&M University, 2004.

[39] J. H. Lee, R. H. Byrne, Geochim. Cosmochim. Acta 56 (1992) 1127-1137.

[40] D. G. Brookins, in: Aqueous geochemistry of rare earth elements, P. H. Ribbe (Ed.), The Mineralogical Society of America: Washington, 1989, pp 201-225.

[41] J. E. Post, P. Natl. Acad. Sci. USA 96 (1999) 3447-3454.

[42] J. W. Murray, J. Colloid Interface Sci. 46 (1974) 357-371.

[43] R. M. Cornell, U. Schwertmann, in The iron Oxides, John Wiley and Sons, USA, 2003, p 703.

[44] H. Elderfield, Philos. T. Roy. Soc. A A325 (1988) 105-126.

[45] K. M. Towe, Palaeogeogr. Palaeocl. 97 (1991) 113-123. 